\title{
MEDIAÇÃO E CONCILIAÇÃO NOS CARTÓRIOS DE REGISTRO CIVIL DAS PESSOAS NATURAIS, INSTRUMENTO PARA A SOLUÇÃO ALTERNATIVA DE LITÍGIOS E FORTALECIMENTO DA CIDADANIA
}

\author{
Luis Ricardo Bykowski dos Santos ${ }^{1}$ \\ Sebastião Sérgio da Silveira ${ }^{2}$
}

\begin{abstract}
Resumo
Este artigo abordará a realização da conciliação e mediação nos cartórios de registro civil das pessoas naturais como instrumento para a solução de litígios no âmbito do interior do Brasil, especialmente levando em consideração a legislação que determina a necessidade de haver uma unidade de tal serventia extrajudicial em cada cidade, bem como nos municípios de significativa extensão territorial, onde em cada sede distrital deverá estar disponível um registrador civil de pessoas naturais. Com a novel lei de mediação, todas as serventias extrajudiciais passaram a ter possibilidade de realizarem mediações, situação que aponta para uma interiorização efetiva na solução dos litígios, exatamente em pequenas cidades que não sejam sede de comarca judicial ou em distritos localizados em municípios de grande extensão territorial, mas que tenham uma unidade de registro civil de pessoas naturais.
\end{abstract}

Palavras-chave: Registro Civil. Solução de litígios. Mediação. Conciliação.

\section{MEDIATION AND CONCILIATION IN CIVIL REGISTRY CARDS OF NATURAL PERSONS, INSTRUMENT FOR THE ALTERNATIVE SOLUTION OF DISPUTES AND STRENGTHENING OF CITIZENSHIP}

\begin{abstract}
This article will deal with conciliation and mediation in civil registration offices of natural persons as a tool for the settlement of disputes within the Brazilian interior, especially taking into account the legislation that determines the need for a unit of such extrajudicial service in Each city, as well as in municipalities of significant territorial extension, where a civil registry of natural persons must be available in each district. With the novel law of mediation, all extrajudicial services have been able to carry out mediations, a situation that points to an effective internalization in the solution of

\footnotetext{
1 Delegado de Polícia Civil do Estado do Rio Grande do Sul (aposentado). Capitão da reserva da Polícia Militar do Estado do Rio Grande do Sul. Registrador Civil de Pessoas Naturais do Estado de São Paulo. Especialista em Ciências Penais pela Universidade Federal do Rio Grande do Sul. Especialista em Direito Registral Imobiliário com ênfase em Direito Notarial pelo Centro Universitário Leonardo da Vinci. Mestrando em Direitos Coletivos pela Universidade de Ribeirão Preto. E-mail: delricardob@globo.com. http://lattes.cnpq.br/4164180210369816.

Mestre em Direito pela Pontifícia Universidade Católica de São Paulo. Doutor em Direito pela Pontifícia Universidade Católica de São Paulo e Pós-Doutor pela Faculdade de Direito da Universidade de Coimbra-Portugal. Atualmente é o $8^{\circ}$ Promotor de Justiça de Ribeirão Preto, do Ministério Público do Estado de São Paulo. Professor Titular da Universidade de Ribeirão Preto, onde é Coordenador do Curso de Pós-Graduação em Direito e Professor Doutor do Departamento de Direito Público da Faculdade de Direito de Ribeirão Preto, da Universidade de São Paulo - FDRP-USP. E-mail: sebastiao_silveira@hotmail.com. http://lattes.cnpq.br/7795231195922277.
} 
disputes, precisely in small cities that are not judicial district headquarters or in districts located in large municipalities Territorial extension, but which have a civil registry unit of natural persons.

Keywords: Civil Registry. Dispute settlement. Mediation. Conciliation.

\section{INTRODUÇÃO}

Este artigo tem por objetivo analisar a realização de mediação e conciliação nos cartórios de Registro Civil das Pessoas Naturais como instrumento da interiorização da solução de litígios no Brasil, em razão da nova legislação que regulamentou o instituto da mediação em solo pátrio, norma que também possibilitou aplicação nas serventias registrais e notariais brasileiras.

Para uma exata compreensão do assunto, traçaremos algumas considerações sobre o sistema extrajudicial nacional, composto não só pelos registradores, mas também pelos notários, motivo pelo qual se faz necessário trazer algumas diferenciações sobre os serviços com ocorrência em nosso país, dando especial atenção, como já colocado, ao Registro Civil das Pessoas Naturais.

Abordaremos a natureza jurídica da função extrajudicial, em razão de que tanto doutrina como também a jurisprudência, tem de forma majoritária entendido que os registradores e notários não são essencialmente funcionários públicos, em que pese a função exercida e só haver posse como titulares de suas delegações após aprovação em concurso público de provas e títulos na forma prevista pela Constituição Federal.

Buscando a exata possibilidade da mediação e conciliação, estudaremos a legislação federal e as normas da Corregedorias de Justiça dos estados que já regulamentaram a matéria, além de outros importantes aspectos do instrumento, sem dúvida haverá uma maior possibilidade do exercício da cidadania nas serventias extrajudiciais nos mais diversos rincões do país, o que possibilitará melhores condições para defesa da cidadania e dos direitos humanos, além de oportunizar eventual tutela de direitos coletivos.

Por fim, buscaremos apontar a forma prática de como o serviço será oferecido a população pelos registradores civis de pessoas naturais no âmbito de suas circunscrições, logicamente cotejando com as normas de serviço do Poder Judiciário dos estados. 


\section{MEDIAÇÃO E CONCILIAÇÃO}

A mediação e conciliação devem ser vistas como verdadeiros instrumentos alternativos para a solução de conflitos entre pessoas, deixando claro que elas colocam as partes em uma situação de isonomia, tornando possível uma comunicação igualitária, uma vez que não são consideradas como adversárias, mas sim como indivíduos que buscam uma composição racional e adequada para o problema.

Neste enquadramento, a intervenção do mediador é pela busca pelo diálogo, uma solução que seja encontrada em um caminho mais suave, sem a normal conflituosidade de um processo judicial, não havendo ganhadores ou perdedores, mas sim pessoas que chegam a um acordo, um caminhar sereno que transforma um conflito em uma solução pacífica e, no dizer de Paulo Afonso Brum Vaz (2014), surge como "outra chance, diante do insucesso da aposta no Estado como única e soberana instância, para o resgate da autonomia de pessoas físicas e jurídicas na solução dos seus conflitos e um remédio para a crise de funcionamento do aparato judicial."

Respeitando os princípios da informalidade, simplicidade, economia processual, celeridade, oralidade e flexibilidade processual, a mediação e a conciliação se apresentam como importante instrumento extrajudicial para solução de conflitos.

No que diz respeito aos mediadores e conciliadores, devem estes também observar princípios fundamentais para o escorreito desempenho da função, quais sejam: confidencialidade, decisão informada, competência, imparcialidade, independência e autonomia, respeito à ordem pública e às leis vigentes, empoderamento e validação, tudo na forma estabelecida na Resolução n. ${ }^{\circ}$ 125/2010 do Conselho Nacional de Justiça.

Segundo Tiago França Moraes, a diferença entre a mediação e a conciliação decorre, principalmente, da atuação dos mediadores e conciliadores na busca da resolução do conflito:

[...] verifica-se que na mediação, o mediador tem o dever de conduzir a discussão da maneira mais amena possível, evitando proferir opiniões próprias, mas guiando as partes para que elas mesmas alcancem a pacificação. O mediador deve ainda instruir as partes a chegarem ao acordo, mas sem palpitar no mérito da questão, orientando-as acerca das prováveis consequências de uma "aventura" judicial. Nessa modalidade de solução de controvérsias, as próprias partes decidem, o mediador é o guia, o qual não detém poder decisório. Ao contrário, na conciliação, há uma intervenção um tanto quanto mais objetiva do conciliador, ele pode, por exemplo, sugerir um "meio termo", proferir opiniões, sugestões, etc. É claro, o conciliador (assim como o mediador) devem atentar-se para as questões de ordem pública em 
toda a sua atuação, não permitindo acordos contrários ao bom costume, à ética e ao direito. (2012)

Feitas tais colocações e expostas as diferenças, partimos agora para traçar considerações mais específicas sobre a Lei $\mathrm{n}^{\mathrm{o}}$ 13.140, de 26 de junho de 2015, a chamada Lei da Mediação, norma que passou a dispor sobre a mediação entre os particulares como meio alternativo de solução de controvérsias e sobre a autocomposição de conflitos no âmbito da administração pública, sendo esta a legislação que regulamenta a matéria em solo pátrio e que também se coaduna com as posições expressas no nosso atual Código de Processo Civil, Lei no 13.105 , de 16 de março de 2015.

As recentes legislações tiveram o condão de dar maior celeridade para a solução de conflitos, em razão do conhecido "congestionamento" enfrentado nas ações judiciais, situação já bem definida e no mais das vezes utilizada de forma oportunista pela parte mais forte do conflito, situação identificada por Rodolfo de Camargo Mancuso:

Uma das consequências da morosidade do Judiciário é a possibilidade de que esse órgão venha a ser utilizado de forma oportunista, ou seja, a parte mais forte do conflito que sabe que vai perder prefere entrar na justiça e esperar cerca de dez anos não pagando juros até que a lide seja julgada. (2011, p. 27)

A atual legislação delineou a forma de aplicação do instrumento, aspectos gerais e específicos, entre eles, já no artigo $5^{\circ}$, parágrafo único ${ }^{3}$, impor a necessidade de que a pessoa que servirá de mediadora seja imparcial, devendo ela, para cumprir a determinação e antes da aceitação da função, dar ciência as partes de qualquer tipo de problema, ou seja, de possível impedimento ou suspeição que possa comprometer a sua capacidade de mediar o conflito, podendo desta forma ser recusada por qualquer das partes.

Quanto a escolha do mediador extrajudicial, segue o artigo $9^{\circ}$ da citada lei $^{4}$ informando que qualquer pessoa capaz e que desperte a confiança das partes, poderá atuar como mediador extrajudicial, independentemente de integrar conselho de classe

\footnotetext{
3 Art. $5^{\circ}$. Parágrafo único. A pessoa designada para atuar como mediador tem o dever de revelar às partes, antes da aceitação da função, qualquer fato ou circunstância que possa suscitar dúvida justificada em relação à sua imparcialidade para mediar o conflito, oportunidade em que poderá ser recusado por qualquer delas.

$4 \quad$ Art. $9^{\circ}$. Poderá funcionar como mediador extrajudicial qualquer pessoa capaz que tenha a confiança das partes e seja capacitada para fazer mediação, independentemente de integrar qualquer tipo de conselho, entidade de classe ou associação, ou nele inscrever-se.
} 
ou associação, ou seja, um vínculo de segurança se estabelece fundamentando na independência e na imparcialidade, constituindo uma singular alternativa de solução para o desafogamento do Poder judiciário.

Já quanto aos mediadores judiciais, o artigo 11 da Lei da Mediação ${ }^{5}$ estabelece como requisitos necessários para o exercício da função a graduação, com duração mínima de dois anos, em curso de ensino superior de instituição reconhecida pelo Ministério da Educação além da capacitação em escola ou instituição de formação de mediadores reconhecida pela Escola Nacional de Formação e Aperfeiçoamento de Magistrados (ENFAM) ou pelos tribunais.

$\mathrm{O}$ artigo $12^{6}$ segue informando que somente os mediadores judiciais inseridos no cadastro dos tribunais serão considerados habilitados e autorizados a atuar em mediação judicial, bem como o artigo $25^{7}$ da mesma lei estabelece que a designação dos mediadores para o processo independe da prévia aceitação das partes, logicamente se não houver impedimento ou suspeição do mediador na forma antes indicada.

E, mais adiante, o artigo 42 da Lei de Mediação ${ }^{8}$ finalmente dispõe sobre a possibilidade de que as serventias extrajudiciais efetivamente exerçam tal função, solucionando uma grande quantidade de litígios em benéfica atuação em prol da sociedade, salientando que a mesma legislação assegura que o acordo feito no cartório terá efeito de coisa julgada, constituindo um título executivo extrajudicial, forte no parágrafo único do art. $20^{9}$ da mesma lei.

Compreender a natureza jurídica da atividade dos notários e registradores é relevante para entender a sistemática da modificação em curso. Nesse sentido, necessário transcrever o que ensina Hely Lopes Meirelles sobre o serviço:

Agentes delegados são particulares que recebem a incumbência da execução de determinada atividade, obra ou serviço público e o realizam em nome

$5 \quad$ Art. 11. Poderá atuar como mediador judicial a pessoa capaz, graduada há pelo menos dois anos em curso de ensino superior de instituição reconhecida pelo Ministério da Educação e que tenha obtido capacitação em escola ou instituição de formação de mediadores, reconhecida pela Escola Nacional de Formação e Aperfeiçoamento de Magistrados - ENFAM ou pelos tribunais, observados os requisitos mínimos estabelecidos pelo Conselho Nacional de Justiça em conjunto com o Ministério da Justiça.

Art. 12. Os tribunais criarão e manterão cadastros atualizados dos mediadores habilitados e autorizados a atuar em mediação judicial.

7 Art. 25. Na mediação judicial, os mediadores não estarão sujeitos à prévia aceitação das partes, observado o disposto no art. $5^{\circ}$ desta Lei.

$8 \quad$ Art. 42. Aplica-se esta Lei, no que couber, às outras formas consensuais de resolução de conflitos, tais como mediações comunitárias e escolares, e àquelas levadas a efeito nas serventias extrajudiciais, desde que no âmbito de suas competências.

9 Art. 20. Parágrafo único. O termo final de mediação, na hipótese de celebração de acordo, constitui título executivo extrajudicial e, quando homologado judicialmente, título executivo judicial. 
próprio, por sua conta e risco, mas segundo as normas do Estado e sob a permanente fiscalização do delegante. Esses agentes não são servidores públicos, nem honoríficos, nem representantes do Estado; todavia, constituem uma categoria a parte de colaboradores do Poder Público. Nessa categoria encontram-se os concessionários e permissionários de obras e serviços públicos, os serventuários de ofícios não estatizados, os leiloeiros, os tradutores e intérpretes públicos, as demais pessoas que recebem delegação para a prática de alguma atividade estatal ou serviço de interesse coletivo. (1995, p. 76)

Importante ainda ressaltar que ao buscar solucionar a demanda em uma serventia extrajudicial, a parte poderá ou não estar representada por advogado, mas caso apenas uma das partes esteja assistida, o mediador suspende o procedimento até que a outra parte também esteja devidamente acompanhada por defensor legal, o que mais uma vez aponta pela evolução racional para a solução do litígio.

\section{PROVIMENTO DA CORREGEDORIA GERAL DE JUSTIÇA DO ESTADO DE SÃO PAULO}

A situação paulista merece uma pormenorizada análise em razão das medidas adotadas no âmbito da Corregedoria Geral da Justiça (CGJ) do Estado de São Paulo (SP), dado a regulamentação da matéria através do Provimento CGJ n. o 17/2013 (2017), de 27 de maio de 2013, bem como inseriu o item 44.2, na Subseção I, da Seção III, do Capítulo XIII, do Tomo II, das Normas de Serviço da Corregedoria Geral da Justiça.

Nos termos do citado provimento, os notários e registradores paulistas foram, então, autorizados a realizar mediação e conciliação nas serventias extrajudiciais onde fossem titulares. Sobre a mediação e a conciliação propriamente ditas, o Órgão Judicial determinou que deveriam ocorrer em sala ou ambiente reservado e discreto nas Serventias, durante o horário de atendimento ao público e versar somente sobre direitos patrimoniais disponíveis e que poderiam atuar como mediador ou conciliador, o titular da delegação ou seu preposto expressamente autorizado e, como requerente ou requerido, a pessoa natural capaz e a pessoa jurídica.

A pessoa natural poderia se fazer representar por procurador devidamente constituído e a pessoa jurídica e o empresário individual poderiam ser representadas por preposto munido de carta de preposição com poderes para transigir, sem haver necessidade de vínculo empregatício, sendo que o requerimento de mediação ou conciliação poderia ser dirigido a qualquer notário ou registrador independentemente da 
especialidade da Serventia Extrajudicial, podendo ser também admitido a formulação de requerimento conjunto firmado pelos interessados.

Quanto a intimação, esta poderia se dar por qualquer meio idôneo de comunicação, como carta com aviso de recebimento (AR), meio eletrônico ou notificação feita por Oficial de Registro de Títulos e Documentos da comarca do domicílio de quem deva recebê-la e, se houvesse opção do interessado, poderia inclusive se dar por meio eletrônico, situação em que não seriam cobradas as despesas pela intimação.

Em que pese a pormenorizada regulação, o Provimento CGJ n. ${ }^{\circ} 31 / 2016^{10}$, revogou o Provimento CGJ n. ${ }^{\circ}$ 17/2013 que possibilitava as mediações e conciliações nas serventias extrajudiciais do Estado de São Paulo.

Tal decisão da Corregedoria Geral de Justiça do Estado de São Paulo merece esclarecimento - primeiramente deve ser colocado que em decisão liminar o Conselho Nacional de Justiça (CNJ) já havia suspendido os efeitos do indicado Provimento CGJ n. $17 / 2013$, tendo, como principal fundamento, a falta de lei que autorizasse tal procedimento.

O segundo problema estava ligado a edição da Lei n. ${ }^{\circ}$ 13.140/2015 que, como já abordado, expressamente previu a possibilidade de as serventias realizarem mediações e conciliações, poderia então se ter como consequência natural o retorno da vigência do Provimento CGJ n. ${ }^{\circ}$ 17/2013.

No entanto, tal não se mostrava adequado em razão de que o próprio Provimento CGJ n. ${ }^{\circ}$ 17/2013 pautava-se na Resolução n. ${ }^{\circ} 125$ do CNJ e, por lógico, não estava em consonância com a Lei n. ${ }^{\circ}$ 13.140/2015, norma ainda não editada na época do primeiro provimento.

Em razão de tais ocorrências, a posição da Corregedoria Geral de Justiça do Estado de São Paulo é no sentido de aguardar a regulamentação da matéria pelo Conselho Nacional da Justiça, em âmbito nacional, conforme decisão publicada no Diário de Justiça do Estado (DJE) de São Paulo em 08 de junho de 2016, de lavra do

10 PROVIMENTO CG N ${ }^{\circ}$ 31/2016. Revoga o Provimento CG 17/13. O DESEMBARGADOR MANOEL DE QUEIROZ PEREIRA CALÇAS, CORREGEDOR GERAL DA JUSTIÇA, NO USO DE SUAS ATRIBUIÇÕES LEGAIS, CONSIDERANDO a necessidade de aperfeiçoamento do texto da normatização administrativa; CONSIDERANDO o exposto, sugerido e decidido nos autos do processo n. ${ }^{\circ}$ 2012/00056888; RESOLVE: Artigo 1 ${ }^{\circ}$ - Revogar o Provimento CG 17/13. Artigo $2^{\circ}$ - Este provimento entra em vigor na data de sua publicação, revogadas as disposições contrárias. São Paulo, 08 de junho de 2016. (a) MANOEL DE QUEIROZ PEREIRA CALÇAS, Corregedor Geral da Justiça. 
Exmo. Sr. Desembargador Manoel de Queiroz Pereira Calças, Corregedor Geral de Justiça de São Paulo. ${ }^{11}$

\section{NORMAS DAS CORREGEDORIAS DE JUSTIÇA DO ESTADO DA BAHIA}

As Corregedorias de Justiça do Estado da Bahia normatizaram a mediação e conciliação em cartórios após a publicação da já indicada Lei no 13.140/2015, sendo que tal regulação foi efetivamente publicada em 14 de maio de 2016, bem como seguiu assinada pelo Exmo. Sr. Desembargador Osvaldo de Almeida Bonfim, Corregedor Geral de Justiça, e pela Exma. Sra. Desembargadora Cynthia Maria Pina Resende, Corregedora das Comarcas do interior do Estado da Bahia.

Nas justificativas da regulação os corregedores baianos entenderam haver possibilidade legal dos notários e registradores prestarem serviços de mediação e conciliação para litígios que versem sobre direitos patrimoniais disponíveis, desde que fosse seguido o disposto pelo Código de Processo Civil e pela Lei da Mediação, até porque, conforme bem ensinam Leopoldo Justino Girardi e Odone José de Quadros (1987, p. 57) "nenhuma lei é feita para um caso particular".

Também consideraram que conforme destacado na Resolução n. ${ }^{\circ} 125$ do Conselho Nacional de Justiça, a conciliação e a mediação são instrumentos efetivos de pacificação social, solução e prevenção de litígios, e que a sua apropriada disciplina em programas já implementados no país tem reduzido a excessiva judicialização dos conflitos de interesses, posição semelhante à adotada pela Corregedoria Geral de Justiça do Estado de São Paulo no primeiro provimento que depois foi revogado.

Palpitantes instrumentos para solução dos problemas enfrentados pelas partes, estes dão a elas a fundamental possibilidade de pessoalmente resolver o litígio, o que se coaduna a lição de Mariana França Gouveia (2017) no sentido de que "na mediação, a postura é exatamente a oposta: parte-se do princípio que as partes são as pessoas que melhor colocadas estão para resolver o litígio."

E mais entenderam, que havia necessidade de organizar e uniformizar os

11 Ora, se é assim, a melhor solução é que se revogue o Provimento CG 17/13 e se aguarde a regulamentação da matéria pelo Egrégio Conselho Nacional da Justiça, em âmbito nacional. É o que proponho, de acordo com minuta que segue. Sub censura. São Paulo, 06 de junho de 2016. (a) Swarai Cervone de Oliveira. Juiz Assessor da Corregedoria DECISÃO: Aprovo, pelas razões expostas, a edição do Provimento sugerido, conforme minuta apresentada, a ser publicado, juntamente com o parecer, por três vezes, em dias alternados, no DJE. Publique-se. São Paulo, 08 de junho de 2016. (a) MANOEL DE QUEIROZ PEREIRA CALÇAS, Corregedor Geral da Justiça. 
serviços de conciliação, mediação e outros métodos consensuais de solução de conflitos, para lhes evitar disparidades de orientação e práticas, invocando para isto o já citado parágrafo primeiro do artigo 236 da Constituição Federal ${ }^{12}$, bem como a competência do Poder Judiciário estadual, este como autoridade delegante dos Serviços Notariais e de Registro, desta forma zelando para que esses serviços sejam prestados com rapidez, qualidade satisfatória e eficiência, nos termos do artigo 38 da Lei dos Notários e Registradores (LNR). ${ }^{13}$

Quanto a aspectos práticos principais, normatizaram que os notários e registradores baianos estão autorizados a realizar conciliação e mediação no âmbito da sua circunscrição, além de que a mediação e a conciliação ocorrerão em sala ou ambiente reservado e apropriado, localizado no espaço físico das Serventias e sempre durante o horário de atendimento regular ao público.

Quanto a eventuais impedimento e suspeição, o mediador terá o regulamentar dever de revelar às partes, antes da aceitação da função, qualquer fato ou circunstância que possa suscitar dúvida justificada em relação à sua imparcialidade para mediar o conflito, oportunidade em que poderá ser recusado por qualquer delas.

No que diz respeito ao objeto, regularam que somente os direitos patrimoniais disponíveis poderão ser objeto das mediações e conciliações extrajudiciais, versando sobre todo o conflito ou voltadas para parte dele.

$\mathrm{Na}$ condição de mediador ou conciliador, somente o titular da delegação ou preposto deste estarão autorizados a realização da mediação ou conciliação, para conflitos em que a pessoa natural capaz e a pessoa jurídica estejam devidamente representadas na forma da lei, ainda que a pessoa jurídica e o empresário individual poderão ser representados por preposto, mesmo que sem vínculo empregatício, mas munido de carta de preposição com poderes para transigir.

Além de diversos outros aspectos, a regulação baiana também previu a necessidade de livros próprios na serventia para disponibilização do serviço, a

\footnotetext{
12 Art. 236. $§ 1^{\circ}$ - Lei regulará as atividades, disciplinará a responsabilidade civil e criminal dos notários, dos oficiais de registro e de seus prepostos, e definirá a fiscalização de seus atos pelo Poder Judiciário.

${ }_{13} \quad$ Art. 38. O juízo competente zelará para que os serviços notariais e de registro sejam prestados com rapidez, qualidade satisfatória e de modo eficiente, podendo sugerir à autoridade competente a elaboração de planos de adequada e melhor prestação desses serviços, observados, também, critérios populacionais e sócio-econômicos, publicados regularmente pela Fundação Instituto Brasileiro de Geografia e Estatística.
} 
possibilidade de uso de um formulário padrão para apresentação do pedido pelas partes e da informação de que o termo de mediação ou de conciliação é título executivo extrajudicial, definindo ainda orientação de que não obtido o acordo ou em caso de desistência do requerimento, o procedimento será arquivado pelo notário ou registrador, com registro no denominado Livro de Mediação e Conciliação.

Disposição importante estabelece que os cartorários deverão observar os prazos mínimos de arquivamento de 5 (cinco) anos para os documentos relativos à conciliação ou mediação, além de restar autorizado a eliminação dos documentos quando microfilmados ou gravados por processo eletrônico de imagens.

No que diz respeito às custas do serviço, até que seja editada lei estadual específica, os emolumentos devidos pelo ato praticado pelo tabelião ou pelo registrador serão recolhidos como atos com valor econômico, na forma prevista pela Tabela de Custas do Tribunal de Justiça do Estado da Bahia (TJBA) e Lei Estadual no 12.373, de 23 de dezembro de 2011, sendo que nos casos em que não seja possível identificar a repercussão econômica do acordo contido no termo de mediação ou de conciliação, as despesas serão calculadas como atos sem valor econômico, também na forma descrita pela já indicada Tabela de Custas do TJBA, ressaltando que, conforme leciona Reinaldo Velloso dos Santos (2006, p. 10), o cartorário "para exercer suas atividades e arcar com todas as despesas para a eficiente prestação dos serviços e eventual reparação civil de danos, os notários e oficiais de registro têm direito à percepção integral de emolumentos pelos atos praticados."

Arquivado o procedimento antes da primeira sessão de mediação ou conciliação, serão devidos apenas os emolumentos relativos à notificação dos interessados, devidos como demais atos dos Oficiais de Registro de Imóveis, também pela forma prevista pela Tabela de Custas do Tribunal de Justiça do Estado da Bahia, com a ressalva de que iniciada a primeira sessão de mediação ou conciliação, não haverá devolução do valor pago.

A norma regulatória ainda exige que os registradores e notários baianos que optarem por prestar serviços de mediação e conciliação, solicitem autorização prévia para uma das Corregedorias competentes para apreciar o pleito, ou seja, para a Corregedoria Geral de Justiça ou para a Corregedoria das Comarcas do interior do Estado da Bahia, devendo ser ressaltado que a partir da concessão é vedado ao cartorário autorizado negar, discricionariamente, a prestação do serviço de mediação ou 
conciliação.

\section{NORMAS REGULAMENTARES DA CORREGEDORIA DO ESTADO DE} ALAGOAS

A Corregedoria Geral de Justiça do Estado de Alagoas determinou a publicação, em 26 de julho de 2016, do Provimento n. ${ }^{\circ}$ 36, tendo este disposto sobre a adequação e a instrumentalização dos conflitos de interesse por intermédio da mediação e conciliação no âmbito das serventias extrajudiciais.

Entre as justificativas para a expedição do referido provimento, foram elencadas as disposições encartadas na Lei da Mediação, bem como no Código de Processo Civil, além da possibilidade de desjudicialização, transferindo-se então aos notários e registradores de Alagoas a prestação de serviços de mediação e conciliação nas situações que versem sobre direitos patrimoniais disponíveis, cuja providência não exija a prolação de uma decisão do Estado-Juiz.

De maneira objetiva, a Corregedoria de Justiça alagoana autorizou aos cartorários a realizar mediação e conciliação nas serventias de que são titulares, inovando ao restringir esta atribuição somente ao preposto que for nomeado como primeiro substituto.

De maneira semelhante à descrita em outras normas, também dispôs que a mediação e a conciliação ocorrerão em sala destinada a tal fim nas serventias dos titulares de delegação, durante o horário de atendimento ao público e que os conflitos somente poderão ter referência a direitos patrimoniais disponíveis.

Quanto aos emolumentos e despesas pertinentes aos atos, os cartorários poderão exigir depósito prévio dos valores aos mesmos, sendo que em caso de não ser obtido o acordo ou em caso de desistência do requerente, o procedimento será arquivado pelo cartorário, que registrará essa circunstância no denominado Livro de Conciliação e Mediação, situação semelhante a regulação baiana.

Em caso de arquivamento sem acordo, o notário ou registrador restituirá ao requerente o valor recebido a título de depósito prévio, observadas as seguintes escalas: noventa por cento do total recebido, se o arquivamento ou seu pedido ocorrer antes da sessão de mediação ou conciliação; e, cinquenta por cento, quando infrutífera a sessão de mediação ou conciliação. 
No que diz respeito a escrituração, o Livro de Conciliação e Mediação poderá ser escriturado em meio eletrônico e o traslado do termo respectivo poderá ser disponibilizado na rede mundial de computadores para acesso restrito, mediante a utilização de código específico fornecido às partes.

No que se refere a intimação, os valores pagos para suportar as despesas com a mesma não serão restituídos em qualquer hipótese, salvo quando o requerente desistir do procedimento antes da Serventia realizar o gasto respectivo.

Importante salientar ser vedado ao cartorário receber das partes qualquer objeto ou quantia, exceto os valores relativos às despesas de intimação e aos emolumentos, cenário que aponta para a necessidade da ética e profissionalismo no exercício da função.

Quanto ao arquivamento dos documentos relativos à conciliação ou mediação houve uma inovação ao determinar que os prazos mínimos de arquivamento serão de apenas 3 (três) anos, com a ressalva de que para os documentos microfilmados ou gravados por processo eletrônico de imagens não subsiste a obrigatoriedade de sua conservação.

A norma alagoana também faz considerações sobre a necessidade dos cartorários que optarem por prestar serviços de mediação e conciliação comuniquem formalmente tal fato ao Corregedor Geral da Justiça, sendo também fundamental que tenham realizado curso de qualificação para o exercício da função, bem como, a cada período de 2 (dois) anos, contados da autorização, comprovem a realização de curso de reciclagem em mediação e conciliação ou o empreendimento de esforço contínuo de capacitação na referida área.

\section{INTERIORIZAÇÃO}

Abordadas as normas estatais sobre a mediação e conciliação, buscamos agora estabelecer sua importância no âmbito do interior do Brasil, ressaltando então que em nosso país, em cada município ou distrito localizado a grande distância da sede, deve haver um Registro Civil de Pessoas Naturais na forma prevista nos parágrafos segundo e terceiro do artigo 44 da Lei dos Notários e Registradores (LNR). ${ }^{14}$

14 Art. 44. Verificada a absoluta impossibilidade de se prover, através de concurso público, a titularidade de serviço notarial ou de registro, por desinteresse ou inexistência de candidatos, o juízo 
O fundamento de nosso trabalho se dá exatamente sobre este prisma, sendo o Registro Civil de Pessoas Naturais justamente a especialidade de serventia extrajudicial com maior ocorrência em nosso país, logicamente serão nelas em que a mediação e conciliação terão a maior probabilidade de ocorrência, sendo uma segura alternativa para as partes, pois no dizer de Luiz Guilherme Loureiro (2013, p. 3), os cartorários "são profissionais independentes, devendo obediência apenas a lei e aos regulamentos editados pelo Poder Judiciário.”

E com o Poder Judiciário abarrotado de processos, a utilização do sistema extrajudicial se apresenta como uma solução viável para o problema relatado por Maria de Fátima Batista Meguer e Andrea Abrahão Costa:

Não adianta oferecer mais do mesmo, encorpar a estrutura do judiciário não vai produzir o efeito de sorver a demanda crescente de litígios, pois estes decorrem das relações entre as pessoas e a cada dia a possibilidade de ampliar estas relações eleva-se vertiginosamente, ganham novos facetas e fazem surgir novos direitos antes não concebidos. (2012)

Nesta realidade, nos estados com grande população e maior número de comarcas talvez não se tenha a exata noção da importância da realização da mediação e da conciliação nas serventias extrajudiciais, mas nas mais longínquas regiões, a salutar providência estabelecerá a dimensão do acerto da medida e, no dizer de Rogério Portugal Bacellar, presidente da Associação dos Notários e Registradores do Brasil, "o objetivo é facilitar a vida do cidadão que precisa de soluções cada vez mais ágeis e acessíveis para suas demandas.” (BRASILIENSE, ANOREG-BR, 2016).

Vejamos por exemplo o Estado do Amazonas, onde as sedes das comarcas são relativamente poucas quando considerada a grande extensão territorial total do ente estatal, além de ser comparativamente muito menor o número total das mesmas quando utilizado como parâmetro as percentualmente existentes em outros entes da federação, considerando que apenas 69 (sessenta e nove) serventias extrajudiciais estão localizadas no interior do ente federativo, conforme descreve o sítio do Tribunal de Justiça do Estado do Amazonas (2017).

A possibilidade do acesso ao Poder Judiciário no citado estado, localizado em parte da floresta amazônica, certamente apresenta grande dificuldade e, no mais das vezes, sequer compensa financeiramente o deslocamento da parte para buscar a proteção

competente proporá à autoridade competente a extinção do serviço e a anexação de suas atribuições ao serviço da mesma natureza mais próximo ou àquele localizado na sede do respectivo Município ou de Município contíguo. 
estatal, uma vez que se tem notícia da necessidade de longas viagens por vias pluviais, com duração de vários dias, para que seja garantido acesso à cidade mais próxima.

No entanto, vejamos o caso do indivíduo que tenha domicílio em uma pequena cidade do interior daquele estado nortista, situado este município a grande distância da sede da comarca e, como exemplo, que a referida pessoa necessite a tutela jurisdicional para solução de uma lide referente a direitos disponíveis.

Ora, se houver um Registro Civil de Pessoas Naturais com possibilidade legal de realizar a mediação e conciliação, logicamente mais um meio eficaz para solução da lide se apresentará, bem como tal providência possivelmente seja mais econômica.

Logicamente a busca de um julgador para solução da lide poderá parecer mais moderada financeiramente, mas quando computados os custos de deslocamento, bem como seja o serviço extrajudicial prestado de forma adequada, no domicílio dos envolvidos, além de que a solução seja obtida em curto lapso temporal, logicamente as partes alcançarão a satisfação de seu problema e a pacificação social terá sido encontrada.

Nesta realidade, ressaltamos que as serventias extrajudiciais também possuem importância reconhecida pelos usuários dos serviços, uma relação de confiança com a coletividade restou evidenciada pelo Instituto Datafolha, quando em pesquisa de opinião realizada no ano de $2015^{15}$ nas cidades de Brasília, São Paulo, Rio de Janeiro, Curitiba e Belo Horizonte, os cartórios atingiram o primeiro lugar.

E neste enquadramento, a pessoa física ou jurídica somente buscará o direito

15 Resultados da pesquisa sobre a imagem dos cartórios, realizada pelo Instituto Datafolha. O anúncio apresenta ainda dados da pesquisa Doing Business, realizada pelo Banco Mundial O Instituto Datafolha realizou, no final de 2015, pesquisa junto aos usuários de cartórios de Brasília, São Paulo, Rio de Janeiro, Curitiba e Belo Horizonte: Os entrevistados elegeram os cartórios como a instituição mais confiável do país, dentre todas as instituições públicas e privadas. A pesquisa apontou o nível de satisfação dos usuários com as atividades extrajudiciais. Na avaliação da confiança nas instituições públicas, com notas de 0 a 10, os cartórios conquistaram a primeira posição, com média 7,6, à frente, por exemplo, dos Correios. Já na comparação dos cartórios com todos os demais serviços públicos, $77 \%$ dos usuários consideraram os cartórios ótimos ou bons. A pesquisa ainda apurou que $74 \%$ dos usuários são contra alterações no sistema atual. Ao lado desta credibilidade e qualidade, chama a atenção o resultado do relatório Doing Business, produzido pelo Banco Mundial, segundo o qual o custo de transmissão de imóveis no Brasil (gastos com escritura pública, registro e imposto Municipal) é menor do que o praticado nos países ricos e o da média da América Latina: 3,5\% Brasil (SP), 4,2\% Países Ricos e 6,1\% América Latina. Segundo o presidente da Associação dos Notários e Registradores do Brasil (ANOREG BR), Rogério Portugal Bacellar, a avaliação positiva é reflexo do esforço da categoria para aprimorar o sistema extrajudicial e do perfil constitucional que ela ostenta, que compreende a gestão privada, a responsabilidade pessoal dos titulares e a fiscalização do Poder Judiciário. "Nos dedicamos constantemente ao aperfeiçoamento do sistema, investindo em gestão, capacitação e tecnologia a fim de proporcionarmos ao cidadão segurança jurídica e acesso fácil, rápido e seguro às informações e às nossas atividades", ressalta Bacellar. 
que lhe for disponível, procurará a serventia extrajudicial quando lhe aprouver e dentro do lapso temporal previsto para buscar o que, em tese, faz parte de seu patrimônio, na forma do magistério de Rudolf Von Jhering:

[...] enquanto a realização prática do direito público e do penal está assegurada, porque está imposta como um dever aos funcionários públicos, a do direito privado apresenta-se aos particulares sob a forma de direito, isto é, por completo abandonada a sua prática à sua livre iniciativa e à sua própria atividade. (2007, p. 39).

Desta feita, considerados os aspectos objetivos e práticos, as Corregedorias de Justiça dos Estados da Bahia e Alagoas agiram corretamente ao regulamentar a matéria e, certamente, Corregedorias de Justiça de outros estados deverão formalizar normas pertinentes para mediação e conciliação em suas áreas de jurisdição, utilizando o sistema das serventias extrajudiciais, que no dizer de Leonardo Brandelli (2011, p. 154), tem natureza de "direito público e não privado", mas que se configura como fundamental no objetivo da interiorização dos mecanismos de pacificação social.

\section{CONSIDERAÇÕES FINAIS}

Para atingirmos nosso objetivo buscamos apresentar breves noções do sistema extrajudicial nacional, especificando o Registro Civil de Pessoas Naturais em razão da sua importância na vida do país, motivo pelo qual foi importante darmos uma visão geral sobre as origens do sistema para depois incursionarmos sobre os registros brasileiros propriamente ditos.

Particulares em colaboração, a especialidade dos registradores civis tem por função a nobre tarefa de guardar as informações sobre a vida dos brasileiros e de pessoas residentes em nosso país, especialmente sobre o efetivo nascimento, além de outras importantes intercorrências relacionadas a pessoa, como por exemplo, o casamento e a morte, informações estas que constam dos livros das serventias extrajudiciais de todo o Brasil.

Verdadeiros auxiliares do Poder Judiciário, os cartorários não são servidores públicos, não recebem salários e nem são subsidiados pelo governo, em realidade a atividade é sustentada por quem precisa do serviço, fazendo pagamento dos valores referentes aos emolumentos na forma tabeladas pelas Corregedorias de Justiça dos estados. 
E no que se refere aos Registros Civis de Pessoas Naturais, restou bem expresso que são estas as serventias extrajudiciais que representam o maior número de unidades instaladas no país, em razão de que estão presentes em todas as cidades ou distritos brasileiros localizados a grande distância da sede municipal, portanto são as mesmas que de maneira efetiva possibilitarão a cada vez mais necessária interiorização dos mecanismos de solução de conflitos, permitindo então um especial exercício da cidadania.

Como um grande número de cidades não são sede de Comarca Judicial, a possibilidade que os Registros Civis de Pessoas Naturais realizem a mediação e a conciliação na forma prevista pela Lei 13.140/2015, se apresenta como um moderno e racional instrumento de pacificação social, utilizando para isso um sistema extrajudicial já bem ajustado, bem avaliado pela população e em pleno funcionamento no solo pátrio, possibilitando oferecer as partes mais uma opção para buscar a solução de um problema que de outra forma não seria resolvido.

Logicamente as inovações apontam para uma longa caminhada, uma vez que somente com a rotina cartorária de solução dos litígios poderemos concluir que o instrumento alcançará o sucesso almejado, situação que aguarda uma mudança de atitude dos cidadãos e também dos operadores do direito.

Neste descortino, a regulamentação da mediação por parte das Corregedorias de Justiça dos Estados da Bahia e de Alagoas mostram-se fundamentais para assegurar o êxito da medida, bem como possibilita uma real interiorização do instituto para os rincões mais distantes do nosso país, sendo interessante constatar que o Poder Judiciário evolui no caminho adequado, dando oportunidade ao fortalecimento da cidadania, na medida em que o acesso a direitos até então com grande dificuldade ou até impossibilidade de serem exercidos, passam a ter uma chance real de serem alcançados, o que, sem dúvida, acaba fortalecendo a própria percepção de respeito a cidadania.

\section{REFERÊNCIAS}

ALAGOAS (Estado). Provimento $\mathrm{n}^{\circ}$ 36, de 26 de julho de 2016. Dispõe sobre adequação e a instrumentalização dos conflitos de interesse por intermédio da mediação e conciliação no âmbito das serventias extrajudiciais de Alagoas e adota providências correlatas, revogando o Provimento 18, de 05 de agosto de 2013. Provimento n. ${ }^{\mathbf{3 6}}$, de 26 de Julho de 2016: CORREGEDORIA-GERAL DA JUSTIÇA. Pode Judiciário de Alagoas.

Disponível

em: 
Mediação e conciliação nos cartórios de registro civil das pessoas naturais, instrumento para a solução alternativa de litígios e fortalecimento da cidadania

$<$ http://www.tjal.jus.br/corregedoria/provimentos/368745affa8474f765b5da7f605ccbea. pdf>. Acesso em: 24 abr. 2017.

AMAZONAS (Estado). Tribunal de Justiça. Cartórios Interior. 2017. Disponível em: <http://www.tjam.jus.br/index.php?option=com_extrajudicial\&view=locais\&categoriai $\mathrm{ds}=7 \&$ Itemid=1320>. Acesso em: 24 abr. 2017.

BACELLAR, Rogério Portugal. Novo CPC: Mediação e conciliação extrajudicial trazem mudança de paradigma. 2016. Sindicato dos Notários e Registradores do Estado do Espírito Santo. Disponível em: <http://www.sinoreges.org.br/?pG=X19leGliZV9ub3RpY2lhcw==\&in=MzQ0Mw==\&filtro=10>. Acesso em: 24 abr. 2017.

BAHIA (Estado). Provimento Conjunto nº 02, de 16 de maio de 2016. Dispõe sobre mediação e conciliação no âmbito das serventias extrajudiciais da Bahia. Provimento Conjunto n. ${ }^{\circ}$ CGJ/CCI- 02/2016. Disponível em:

<http://www5.tjba.jus.br/corregedoria/images/pdf/provimento_conjunto_02_2016.pdf〉. Acesso em: 24 abr. 2017.

. Lei $\mathrm{n}^{\mathrm{o}} 12.373$, de 23 de dezembro de 2011. Dispõe sobre a fixação, a contagem, a cobrança e o pagamento dos emolumentos relativos aos atos praticados pelos serviços notariais e de registro, da Taxa de Prestação de Serviços na área do Poder Judiciário e da Taxa de Fiscalização Judiciária. Lei n. ${ }^{0} 12.373$ de 23 de Dezembro de 2011. Disponível em: <http://www.sefaz.ba.gov.br/contribuinte/tributacao/Lei.12.37311.pdf $>$. Acesso em: 24 abr. 2017.

BRANDELLI, Leonardo. Teoria Geral do Direito Notarial. São Paulo: Saraiva, 2011.

BRASIL. Constituição da República Federativa do Brasil do Brasil de 1988.

Disponível em:

<http://www.planalto.gov.br/ccivil_03/constituicao/ConstituicaoCompilado.htm>. Acesso em: 24 abr. 2017.

Lei $\mathrm{n}^{\circ} 13.105$, de 16 de março de 2015. Código de Processo Civil. Lei n. ${ }^{\circ}$ 13. 105/2015. Disponível em: <http://www.planalto.gov.br/ccivil_03/_ato20152018/2015/lei/113105.htm>. Acesso em: 24 abr. 2017.

. Lei $\mathrm{n}^{\mathrm{o}} 8.935$, de 18 de novembro de 1994. Regulamenta o art. 236 da Constituição Federal, dispondo sobre serviços notariais e de registro. (Lei dos cartórios). Lei 8.935/1994. Disponível em: <http://www.planalto.gov.br/ccivil_03/leis/L8935.htm>. Acesso em: 24 abr. 2017.

Resolução nº 125, de 29 de novembro de 2010. Dispõe sobre a Política Judiciária Nacional de tratamento adequado dos conflitos de interesses no âmbito do Poder Judiciário e dá outras providências. Resolução no 125 de 29/11/2010: Conselho Nacional de Justiça. Disponível em: <http://www.cnj.jus.br/busca-atosadm?documento=2579>. Acesso em: 24 abr. 2017.

BRASILIENSE, Jornal Correio; ANOREG-BR, Assessoria de Imprensa da. Confiança 
dos brasileiros nos cartórios é destaque em pesquisa do Datafolha. 2016. Anúncio publicado pela Anoreg Brasil, no Jornal Correio Brasiliense, em 22/03/2016, página 3, apresentando resultados da pesquisa sobre a imagem dos cartórios, realizada pelo Instituto Datafolha. O anúncio apresenta ainda dados da pesquisa Doing Business, realizada pelo Banco Mundial. Disponível em:

$<\mathrm{http}$ ://www.anoreg.org.br/index.php?option=com_content\&view=article\&id=26641:co nfianca-dos-brasileiros-nos-cartorios-e-destaque-em-pesquisa-dodatafolha\&catid=19:destaque\&Itemid=180>. Acesso em: 24 abr. 2017.

GIRARDI, Leopoldo Justino e, Quadros, Odone José de. Filosofia. Porto Alegre: Editora Acadêmica Ltda. 1987.

GOUVEIA, Mariana França. Mediação e Processo Civil, 2017, On line. Professora da Faculdade de Direito da Universidade Nova de Lisboa. Disponível em:

<http://scholar.googleusercontent.com/scholar?q=cache:H6ndygGt5wQJ:scholar.google $. c o m /+$ mariana + frança + gouveia\&hl=pt-BR\&as_sdt=0,5\&as_vis=1>. Acesso em: 24 abr. 2017.

JHERING, Rudolf Von. A Luta pelo direito. $23^{\mathrm{a}}$ ed. Rio de Janeiro: Forense, 2007.

LOUREIRO, Luiz Guilherme. Registros Públicos. São Paulo: Editora Método, 2013.

MANCUSO, Rodolfo de Camargo. Acesso à justiça - condicionantes legítimas e ilegítimas. São Paulo: Editora Revista dos Tribunais, 2011.

MEIRELLES, Hely Lopes. Direito administrativo brasileiro. São Paulo: Malheiros, 1995.

MEGUER, Maria de Fatima Batista; COSTA, Andrea Abrahão. Arbitragem, conciliação e mediação: meios adequados de remoção de obstáculos à pacificação social? Ấmbito Jurídico, Rio Grande, XV, n. 107, dez 2012, On line. Disponível em: < http://www.ambito-

juridico.com.br/site/?n_link=revista_artigos_leitura\&artigo_id=12367

>. Acesso em: 24 abr. 2017.

MENGUER, Maria de Fátima Batista e; COSTA, Andrea Abrahão. Arbitragem, conciliação e mediação: meios adequados de remoção de obstáculos à pacificação social? Disponível em: <http://www.ambito-

juridico.com.br/site/?n_link=revista_artigos_leitura\&artigo_id=12367>. Acesso em 17 abr. 2017.

MORAES, Tiago França. A mediação, a conciliação e a arbitragem como formas alternativas de resolução de conflitos. Revista Jus Navigandi, ISSN 1518-4862, Teresina, ano 17, n. 3346, 29 ago. 2012, On line. Disponível em:

<https://jus.com.br/artigos/22520>. Acesso em: 24 abr. 2017.

SANTOS, Reinaldo Velloso dos. Registro Civil das Pessoas Naturais. Brasil: Versão Digital, 2006. 144 p. Disponível em: <http://reinaldovelloso.not.br/resources/Registro Civil das Pessoas Naturais.pdf>. Acesso em: 24 abr. 2017. 
SÃO PAULO (Estado). Provimento no 17, de 05 de junho de 2013. Autoriza e implementa a mediação e a conciliação extrajudicial no Estado de São Paulo e insere o item 44.2, na Subseção I, da Seção III, do Capítulo XIII, do Tomo II, das Normas de Serviço da Corregedoria Geral da Justiça. Provimento CGJ n. ${ }^{\circ}$ 17/2013. DJE de 06/06/2013, p. 17 Republicação: DJE 10.6.13, p.16; 12.6.13, p. 17 Revogado pelo Provimento CG 31/2016. Disponível em:

<https://esaj.tjsp.jus.br/gcnPt1/abrirDetalhesLegislacao.do?cdLegislacaoEdit=109332\&f lBtVoltar=N>. Acesso em: 24 abr. 2017.

Provimento $\mathrm{n}^{\circ} 31$, de 08 de junho de 2016. Dispõe sobre a revogação do Provimento $\mathrm{n}^{\circ} 17 / 2013$, que regulamenta a forma de como se fariam mediações e conciliações nas serventias extrajudiciais, devido as alterações advindas na Lei $\mathrm{n}$. 13.140/15. (RNN). Provimento CG n. 31/2016: CORREGEDORIA GERAL DA JUSTIÇA DO ESTADO DE S.PAULO. DJE de 13/06/2016, p. 39 Republicação: DJE de 15.06.16, p.14; 17.06.16, p.7. Disponível em:

<https://esaj.tjsp.jus.br/gcnPt1/abrirDetalhesLegislacao.do?cdLegislacaoEdit=145903\&f lBtVoltar=N>. Acesso em: 24 abr. 2017.

VAZ, Paulo Afonso Brum. Lei de mediação e conciliação tem pontos positivos e algumas falhas. Revista Consultor Jurídico, Brasil, 03 jun. 2014, On line. CONJUR. Disponível em: <http://www.conjur.com.br/2015-jul-03/paul-vaz-lei-mediacao-pontospositivos-algumas-falhas>. Acesso em: 24 abr. 2017. 